Journal of Patient-Centered

4-19-2021

\title{
Building Community-Engaged Multidisciplinary Partnerships to Improve Medication Management in Elderly Patients With Multiple Chronic Conditions
}

\author{
Ivy O. Poon \\ Felicia Skelton \\ Lena R. Bean \\ Dominique Guinn \\ Terica L. Jemerson \\ Ngozi D. Mbue \\ Creaque V. Charles \\ Uche Anadu Ndefo
}

Follow this and additional works at: https://aah.org/jpcrr

Part of the Behavior and Behavior Mechanisms Commons, Clinical and Medical Social Work

Commons, Community Health and Preventive Medicine Commons, Geriatrics Commons, and the

Pharmacy and Pharmaceutical Sciences Commons

\section{Recommended Citation}

Poon IO, Skelton F, Bean LR, Guinn D, Jemerson TL, Mbue ND, Charles CV, Ndefo UA. Building communityengaged multidisciplinary partnerships to improve medication management in elderly patients with multiple chronic conditions. J Patient Cent Res Rev. 2021;8:113-20. doi: 10.17294/2330-0698.1778

Published quarterly by Midwest-based health system Advocate Aurora Health and indexed in PubMed Central, the Journal of Patient-Centered Research and Reviews (JPCRR) is an open access, peer-reviewed medical journal focused on disseminating scholarly works devoted to improving patient-centered care practices, health outcomes, and the patient experience. 


\title{
Building Community-Engaged Multidisciplinary Partnerships to Improve Medication Management in Elderly Patients With Multiple Chronic Conditions
}

\author{
Ivy O. Poon, PharmD, ${ }^{1}$ Felicia Skelton, MD, MS, ${ }^{2,3}$ Lena R. Bean, MEd, ${ }^{4}$ Dominique Guinn, $\mathrm{PhD},{ }^{5}$ \\ Terica L. Jemerson, MS, ${ }^{4}$ Ngozi D. Mbue, PhD, APRN, ANP-C, ${ }^{6}$ Creaque V. Charles, PharmD, ${ }^{1}$ \\ Uche Anadu Ndefo, PharmD ${ }^{1}$ \\ ${ }^{1}$ Department of Pharmacy Practice, College of Pharmacy and Health Sciences, Texas Southern University, Houston, TX; \\ ${ }^{2}$ Center for Innovations in Quality, Effectiveness and Safety, Michael E. DeBakey VA Medical Center, Houston, TX; \\ ${ }^{3} \mathrm{H}$. Ben Taub Department of Physical Medicine and Rehabilitation, Baylor College of Medicine, Houston, TX; ${ }^{4}$ Division \\ of Student Services, Texas Southern University, Houston, TX; ${ }^{5}$ Department of Health Kinesiology and Sports Studies, \\ College of Education, Texas Southern University, Houston, TX; ${ }^{6}$ Texas Woman's University, Houston, TX
}
Purpose $\quad$ Many studies in preventing adverse drug events have been researcher-driven, yet few have engaged patients in the development of a project. This project aims to engage minority elderly patients with multiple chronic conditions in the development of research questions and strategies to improve medication safety.

Methods $\quad$ Elderly patients ( $\geq 65$ years old) who were prescribed 7 or more chronic medications were recruited through a university-based aging resource network in a historically African American community in Houston, Texas. Patients and a caregiver participated in a multidisciplinary workgroup comprised of a physician, pharmacists, a nurse, health educators, and a social worker. Patients were engaged by utilizing the 4 patient-centered outcomes research engagement principles. The workgroup created a strategic plan, completed an environmental scan, identified research problems, and reviewed current evidence-based approaches in the literature. Workgroup findings were presented to a broader audience within a community town hall setting, and input was collected from a community-wide survey.

Results $\quad$ From April 2018 to July 2018, 3 patients and 1 caregiver participated in 5 multidisciplinary workgroup meetings. A total of 74 seniors attended the town hall meeting, and 69 completed the surveys. The most common drug-related problems among survey participants were doubts about drug advertisements $(79 \%)$ and drug interactions (70\%). Most participants $(88 \%)$ were more comfortable in receiving face-to-face counseling compared to an app or virtual visits. Findings aided in developing 3 grant proposals.

Conclusions This narrative provides a roadmap for conducting multidisciplinary, patient-centered participatory research to refine research strategies in minimizing drug-related problems. (J Patient Cent Res Rev. 2021;8:113-120.)

Keywords drugs; side effects; adverse reactions; elderly; polypharmacy; patient-centered care; multiple chronic conditions

$\mathrm{A}$ dverse drug event (ADE), defined as injury caused by a medical intervention related to a drug, is a significant health problem in the United States. ${ }^{1}$ ADE accounts for 3.5 million physician office visits, 1 million emergency room (ER) visits, and 125,000

Corresponding author: Ivy O. Poon, PharmD, Department of Pharmacy Practice, Texas Southern University, 3100 Cleburne, Houston, TX 77004 (ivy.poon@tsu.edu) hospital admissions each year. ${ }^{1,2}$ Two major independent risk factors for $\mathrm{ADE}$ are old age and multiple medication use (ie, polypharmacy). ${ }^{2,3}$ According to the U.S. Census, the population of adults age 65 and older has increased from 38.8 million in 2008 to 52.4 million in 2018 (a 35\% increase) and constitutes about $18 \%$ of the U.S. population. ${ }^{4}$ The racial minority percentage is also projected to increase from $19 \%$ of the older adult population in 2008 to $34 \%$ in $2040 .{ }^{4}$ Studies have shown that elderly patients disproportionally experience higher rates of ADE-related ER visit (34.5\% of all ADE-related ER visits are elderly) and hospitalization (43.6\% of those elderly ADE-related 
ER visits result in hospitalization) compared to any age group. ${ }^{5,6}$ African American patients have been reported to experience a higher risk of ADE-related deaths. ${ }^{4}$

Elderly patients have a high prevalence of polypharmacy, with $29 \%$ taking more than 5 medications daily. ${ }^{7}$ This places nearly 1 in 22 older individuals at risk for significant drug-drug interactions. ${ }^{8}$ Medications used for chronic conditions such as anticoagulants, insulin, and opioid analgesics are implicated in about $60 \%$ of ADErelated ER visits. ${ }^{6}$ Most ADEs (50\%-90\%) have been reported to be type A adverse drug reactions, which are dose-related, predictable, and preventable events caused by known pharmacologic effects of drugs. ${ }^{2,9}$

To overcome the critical problem of ADE, the Centers for Medicare \& Medicaid Services developed regulations and guidelines for hospitals, clinics, and nursing homes, in partnership with patients, to promote safe medication use. ${ }^{10}$ Medication reconciliation strategies have had a positive impact on reducing ADEs, but the quality of evidence has been low and the definition of $\mathrm{ADE}$ lacks standardization. ${ }^{11,12}$ Most strategies to improve medication safety have been limited to medication education from provider to patient. $^{13}$ In 2018, a multidisciplinary workgroup comprised of leaders in the fields of cardiovascular disease and aging concluded that more research would be needed to improve patient engagement and communication as well as coordination of care for older patients with multiple comorbidities who encounter multiple health care providers. ${ }^{14}$

To date, few studies in the literature have fully engaged patients as research partners to identify research problems or to design strategies for improvement. Herein, we describe an innovative patient engagement project supported by the Patient-Centered Outcomes Research Institute (PCORI) - involving African American elderly patients with polypharmacy who reside in a single urban community. The primary goal of this project was to identify research problems and refine intervention strategies by engaging minority seniors with polypharmacy in the local community to improve medication safety.

\section{METHODS}

\section{Patient Recruitment}

This project was conducted in the Third Ward community of Houston, Texas, from April 2018 to August 2018. The study protocol was reviewed and approved by the institutional review board of Texas Southern University (Houston, TX). Third Ward is a historically African American community (population: 14,295) located approximately 3 miles from Houston's Texas Medical Center. In 2015, 8\% of individuals residing in Third Ward were 65 years old or older, $67 \%$ were African Americans, 22\% did not have a high school diploma, and $51 \%$ had an income of $<\$ 25,000$ per year. ${ }^{15}$ It is the 15 th most dangerous neighborhood in the United States, where approximately 1 in 13 individuals becomes a victim of a violent crime every year. ${ }^{16}$

The primary participants recruited were African Americans. To reach this specific group in Third Ward, which has been underrepresented in research studies historically, investigators collaborated with a university-based geriatric community network for patient recruitment. This community network has been active in engaging seniors in the Third Ward and Greater Houston for over 20 years. Prior to study recruitment, the pharmacist investigators provided 2 free community health-screening activities at the Third Ward Community Center and the Hobby House (a local gathering home) to engage with local seniors. Each health-screening activity included a presentation about polypharmacy, a blood pressure screening, and a comprehensive medication review.

The director of the geriatric community network assisted with hosting a recruitment event to a senior exercise group that met at Emancipation Park in Third Ward. Investigators presented project goals, eligibility criteria, time commitment, and compensation at the event. Interested parties completed the patient partner consent forms and the eligibility screening forms. Eligibility for participation in the multidisciplinary workgroup included individuals 65 years old or older who consumed 7 or more chronic medications daily and resided in Third Ward.

The project target included recruiting 3 patients and 1 caregiver to participate in a multidisciplinary workgroup focused on improving the safe use of medication. The rationale for selecting a small number of patient partners to participate in the workgroup was to build a close relationship and trust between the researchers and the patient partners in the exploratory stage of the study. The patients and caregiver were termed "patient partners" because they served as partners in the research development. The role of patient partners was to actively participate in each workgroup meeting. Patient partners served as representatives of the Third Ward community at large to share opinions about medication safety. They were selected based on eligibility criteria and their availability to attend workgroup meetings. If more individuals were eligible than the target recruitment number, those individuals would serve as alternates when a patient partner could not attend a meeting.

\section{Stakeholder Recruitment}

Invitations were sent to local health community partners, including city-funded community centers, faith-based 
organizations, university health-related disciplines (health educator program and geriatric community network), and 2 prominent Texas Medical Center-affiliated institutions (medical school and hospital) to form a multidisciplinary workgroup consisting of a physician, nurse, pharmacists, health educators, and social worker. The goal was to recruit at least 1 member from each discipline along with 1 alternate for the workgroup. The role of the physician, nurse, and pharmacist was to provide insights into the identification of research questions and strategies. The role of the health educator and social worker was to serve as gateways to patient recruitment into workgroup and town hall meetings. Health educators were extremely resourceful about existing health-related promotional activities in the community.

\section{Workgroup Tasks}

The overall goal of the workgroup was to engage patient partners in identifying research problems and refining research strategies for medication safety. The workgroup was tasked with 4 activities: 1) create a strategic plan; 2) complete an environmental scan and problem identification; 3) participate in comparative effectiveness review of current evidence-based approaches; and 4) organize a community town hall meeting to solicit input on research strategies from a boarder group of seniors in Third Ward.

An environmental scan was guided by 3 questions modified from the principles of the Asset-Based Community Development process. ${ }^{17}$ The 3 discussion questions were: 1) What community resources have been most helpful for seniors taking multiple medications to improve medication safety? What helps you to be better informed about how to take your medications? 2) How can the Houston community better support seniors who take multiple medications based on existing strengths? What are needs not being met? 3) What help would you need the most right now to improve medication safety? Each workgroup member was encouraged to express his/her opinion and had a chance to speak during the discussions.

Workgroup discussions were recorded and transcribed by research personnel. Transcripts were evaluated by thematic analysis to identify the common consensus of medication safety-related problems experienced by this workgroup.

\section{Literature Search}

Project investigators conducted a literature search via the Texas Medical Center Library One Search database using the terms "polypharmacy," "adverse drug events," "intervention," "elderly," "community," and "pharmacist." Only primary literature and guidelines in an outpatient community setting were included. A lay summary of each article was presented to the workgroup, followed by discussions in 2 workgroup meetings after research problem identification and before research strategy discussion. The summary contained article citation, study population, setting, intervention, results, and conclusion. Patient partners provided comments and feedback on the strategies and outcomes of the studies reviewed.

\section{Community Town Hall and Survey}

Workgroup members assisted with the design, promotion, organization, volunteering, and execution of the community town hall meeting. The town hall included an introduction about patient-centered research, a report about the workgroup activities, sharings from each workgroup member, and a collection of community feedback on the name of the proposed project, medicationrelated problems, and strategies obtained via a written survey. After the presentations, participants were free to visit booths of vendors representing a variety of local health clinics and community organizations. Each participant received a medication organizer (pillbox) and a complimentary lunch.

\section{Engagement Approach}

This project was carried out based on the 4 patientcentered outcomes research engagement principles for engaging a hard-to-reach population: reciprocal relationships, partnerships, co-learning, and transparency-honesty-trust. ${ }^{18}$ In reciprocal relationships, all workgroup members were viewed as equal partners and key personnel. Investigators and workgroup members developed a collaborative strategic plan, which described the role of each member in the decision-making process.

As partners, workgroup members were compensated for their time and effort in attending the workgroup meetings. A mutually agreed contract was established for each workgroup member, which specified hourly pay, time commitment, and job description. The cost for parking to attend workgroup meetings was included in the compensation. The meeting location and time were set according to the patient partners' activity schedule. Investigators traveled to patient partners' preferred meeting locations. Investigators and workgroup members were selected based on expertise in their respective disciplines and the ability to adapt to and meet the cultural needs of this patient partner group.

In co-learning, investigators helped patient partners and community partners to understand the research process and patient-centered research. Peer-reviewed articles were summarized in lay terms (ie, third-grade reading level) and discussed with patient partners. Patient partners and other workgroup members were actively engaged in identifying the research problem and reviewing the potential causes of and solutions for the research problem. 
In transparency-honesty-trust, each patient partner had a chance to express their opinion and cast votes to make decisions. Patient partner votes counted as twice in weight compared to other workgroup members. Decisions made were carried out and reported during the next meeting. Both patient partners and investigators arrived at the meetings on time to show respect for all attendees' time and effort.

\section{RESULTS}

\section{Workgroup}

A total of 24 seniors attended the recruitment event. Of those, 3 individuals and 1 caregiver were interested in and eligible to participate in the project. The workgroup formed consisted of those 4 participants along with 3 pharmacists, 1 physician, 1 nurse, 3 health educators, and 1 social worker. Most workgroup members (90\%) were African Americans. All patient partners were African American women. This collaborative workgroup consisted of representatives from the medical school, the college of pharmacy, the health educator program, 2 Texas Medical Center-affiliated hospitals, and 2 community organizations.
The workgroup had meetings every other week from June to August. Each meeting lasted for approximately 1 hour during lunchtime, of which complimentary food and beverage were provided. Two patient participants attended all 5 meetings; the other patient missed 2 meetings due to a personal conflict. The physician, nurse, pharmacists, caregiver, health educators, and social worker were in attendance for all the meetings. Patient partners were actively engaged in all the meetings, and examples of their involvement are listed in Table 1.

To begin the first workgroup meeting, members played 2 ice-breaker games to meet and greet. The group created a strategic plan consisting of the mission, goals, project period, objectives, membership requirements, role and expectations of workgroup members, meeting dates, decision-making procedures, compensation, and communication methods. The group decided that patients' votes would count double in the decision-making process. The meeting location and time were based on the participants' schedule, either at the Emancipation

Table 1. Summary of Patient Partners' Engagement Activities

\begin{tabular}{|c|c|}
\hline Milestones & Patient Engagement Examples \\
\hline Create a strategic plan & $\begin{array}{l}\text { - Patient partners in the workgroup acted as key personnel for the project by } \\
\text { deciding on the location and time of each meeting. They suggested that the best } \\
\text { time to meet was after their exercise activities, and location varied according to } \\
\text { their exercise schedule. } \\
\text { - Patients' votes counted double in the decision-making process of the workgroup. }\end{array}$ \\
\hline Environmental scan & $\begin{array}{l}\text { - Patients provided input on what has been effective in promoting medication safety } \\
\text { in the community. They mentioned local pharmacy, church, clinic, community } \\
\text { centers, radio, TV, and friends. }\end{array}$ \\
\hline Problem identification & $\begin{array}{l}\text { - Patient partners in the workgroup identified major problems they experience related } \\
\text { to adverse drug events. }\end{array}$ \\
\hline Literature review & $\begin{array}{l}\text { - Investigators presented short summaries of studies on interventions to improve } \\
\text { medication safety by using a standardized template. } \\
\text { - A patient partner found and communicated with the investigator a novel intervention } \\
\text { found on PubMed. }\end{array}$ \\
\hline Community town hall meeting & $\begin{array}{l}\text { - Patients decided on the best time, location, and name of the town hall meeting. } \\
\text { - Patient partners helped with the planning of the town hall meeting. } \\
\text { - Patient partners who participated in the workgroup shared their experiences with } \\
\text { peers in the panel discussion. } \\
\text { - Patients at the town hall voted to decide on the name of the project. They provided } \\
\text { feedback on the importance of research problems identified by the workgroup. }\end{array}$ \\
\hline Identify research strategies & $\begin{array}{l}\text { - Patient partners in the workgroup actively shared the strategies that are most } \\
\text { suitable for themselves and their peers. } \\
\text { - Patient participants in the town hall provided feedback on proposed strategies } \\
\text { through a survey. }\end{array}$ \\
\hline Grant application & $\begin{array}{l}\text { - Patient partners provided letters of support in two Patient-Centered Outcomes } \\
\text { Research Institute grant applications in } 2019 . \\
\text { - Patient partners continued in the National Institutes of Health's Regional Centers in } \\
\text { Minority Institutions grant application under community engagement core activities. }\end{array}$ \\
\hline
\end{tabular}


Park community center or Texas Southern University's recreation center. The strategic plan was reviewed and adopted during the second workgroup meeting for the project period April-August 2018.

Existing resources for medication safety in the communities identified by workgroup members included local pharmacies, clinics, hospitals, a church (a weekly blood pressure screen), community, university programs, radio, TV, relatives, and friends. Patient partners shared their interactions with pharmacists mostly through retail chain pharmacies. They were not familiar with medication therapy management provided by a pharmacist in the ambulatory care clinic. Patient partners shared problems experienced when managing multiple medications, including experiences of having ADEs among themselves, families, and friends. The thematic analysis identified 8 drug-related concerns and problems (Table 2).

Investigators conducted a PubMed literature search that resulted in 6 articles to be reviewed with the workgroup. ${ }^{19-24}$ The presentations of articles described effective strategies to reduce drug-related problems in elderly patients with polypharmacy, such as comprehensive medication reviews and examples of clinical interventions. Based on the evidence presented, the workgroup identified 4 potential strategies that would be appropriate for their target population (Table 3). After the literature review discussion, 1 patient workgroup member found and shared a peer-reviewed article in PubMed on the use of a self-quantification system for personal health information to the group. ${ }^{25}$ As a result, the use of mobile app technology was added to one of the strategies to be surveyed by town hall participants.

\section{Community Town Hall and Survey}

Workgroup members were actively involved in the planning of the town hall meeting. They named the town hall Ready for Action PCORI, created flyers to promote it, provided advice on the type of promotional gifts for attendees, and volunteered on the meeting dates. Ready for Action PCORI had 74 participants (69 female, 5 male) in attendance and booths for 10 community health promotional vendors from the city of Houston, private hospitals, and university-based organizations. The meeting began with an introduction to patient-centered research, followed by introduction of the workgroup members.

A survey consisting of the 8 research problems and 4 potential strategies developed by the workgroup was presented to town hall participants for review, and their input was solicited. Participation in the survey was voluntary. A total of 69 participants completed the survey. The majority of participants agreed to having experienced the following problems: multiple medications prescribed by multiple providers, drug-drug interactions, drug commercials, drug side effects, feeling overwhelmed with the drug information provided, and a lack of home

Table 2. Community Town Hall Survey Respondents on Research Problems

\begin{tabular}{|c|c|c|c|c|c|}
\hline Drug-Related Concerns and Problems* & $\begin{array}{l}\text { Strongly } \\
\text { Agree }\end{array}$ & Agree & Neither & Disagree & $\begin{array}{l}\text { Strongly } \\
\text { Disagree }\end{array}$ \\
\hline $\begin{array}{l}\text { I go to see doctors from different facilities, and each prescribes } \\
\text { new medications. It can get very confusing. }(n=69)\end{array}$ & $23(33 \%)$ & $20(29 \%)$ & $8(12 \%)$ & $10(14 \%)$ & $8(12 \%)$ \\
\hline $\begin{array}{l}\text { I am not able to know if one drug that was given by one } \\
\text { physician will interact with the rest of my medications. }(n=68)\end{array}$ & $22(32 \%)$ & $26(38 \%)$ & $11(16 \%)$ & $7(10 \%)$ & $2(3 \%)$ \\
\hline $\begin{array}{l}\text { I am not sure if the information in drug advertisements is } \\
\text { trustworthy or not. }(n=69)\end{array}$ & $34(49 \%)$ & $21(30 \%)$ & $7(10 \%)$ & $4(6 \%)$ & $3(4 \%)$ \\
\hline $\begin{array}{l}\text { The drug information given with the bottle from the pharmacy } \\
\text { is not helpful. It makes me feel overwhelmed. }(n=69)\end{array}$ & $18(26 \%)$ & $18(26 \%)$ & $10(14 \%)$ & $19(28 \%)$ & $4(6 \%)$ \\
\hline $\begin{array}{l}\text { I take a medication for a problem, but that results in a side } \\
\text { effect that created another problem. }(n=68)\end{array}$ & $20(29 \%)$ & $22(32 \%)$ & $12(18 \%)$ & $10(15 \%)$ & $4(6 \%)$ \\
\hline $\begin{array}{l}\text { My medication costs too much money. I do not take the } \\
\text { prescribed medications every day, and I try to save them } \\
\text { even if they are expired. }(n=69)\end{array}$ & $19(28 \%)$ & $7(10 \%)$ & $14(20 \%)$ & $19(28 \%)$ & $10(14 \%)$ \\
\hline I forget to take my medications. $(n=69)$ & $8(12 \%)$ & $19(28 \%)$ & $14(20 \%)$ & $18(26 \%)$ & $10(14 \%)$ \\
\hline $\begin{array}{l}\text { I do not have a medication list with me, so I cannot tell the } \\
\text { doctor what I am taking in case of an emergency. }(n=68)\end{array}$ & $16(24 \%)$ & $28(41 \%)$ & $11(16 \%)$ & $8(12 \%)$ & $5(7 \%)$ \\
\hline
\end{tabular}

${ }^{*} n<69$ indicates not every participant responded to the question. 
Table 3. Survey Respondent Preferences for Research Interventions

\begin{tabular}{|c|c|c|c|c|c|}
\hline Drug-Related Concerns and Problems* & $\begin{array}{c}\text { Very } \\
\text { Comfortable }\end{array}$ & Comfortable & Neutral & Uncomfortable & $\begin{array}{c}\text { Very } \\
\text { Uncomfortable }\end{array}$ \\
\hline $\begin{array}{l}\text { How comfortable are you to talk to } \\
\text { a health professional to review your } \\
\text { medications? }(n=69)\end{array}$ & $45(65 \%)$ & $16(23 \%)$ & $4(6 \%)$ & $3(4 \%)$ & $1(1 \%)$ \\
\hline $\begin{array}{l}\text { How comfortable are you in using a } \\
\text { medication reminder app through your } \\
\text { smartphone? }(n=67)\end{array}$ & $15(22 \%)$ & $8(12 \%)$ & $24(36 \%)$ & $7(10 \%)$ & $13(19 \%)$ \\
\hline $\begin{array}{l}\text { How comfortable are you in having a virtual } \\
\text { pharmacist visit through a web camera with } \\
\text { the help of a health educator? }(n=67)\end{array}$ & $12(18 \%)$ & $11(16 \%)$ & $23(34 \%)$ & $12(18 \%)$ & $9(13 \%)$ \\
\hline $\begin{array}{l}\text { How comfortable are you in having a } \\
\text { peer buddy or peer group to help with } \\
\text { medication management? }(n=69)\end{array}$ & $10(14 \%)$ & $11(16 \%)$ & $25(36 \%)$ & $14(20 \%)$ & $9(13 \%)$ \\
\hline
\end{tabular}

${ }^{*} n<69$ indicates not every participant responded to the question.

medication lists. Surprisingly, the cost of medications and forgetfulness to take chronic medications were perceived as less-agreed problems.

Most participants $(88 \%)$ were comfortable with receiving face-to-face counseling by a health care professional. They were less comfortable with using a medication management app, having virtual visits with a health care professional, or having a peer to assist with medication management.

\section{Research Project Proposals}

Based on the workgroup feedback and community survey, investigators developed a research proposal featuring a patient-centered intervention study to compare comprehensive medication reviews virtually assisted by a health educator versus face-to-face assistance. The patient partners in this study provided letters of support to express a willingness to serve as patient collaborators. The proposal also expanded the setting to include Houston's Fifth Ward community. The proposal was submitted to a PCORI funding opportunity in 2018 and received comments to improve the proposal in 2019. A revised proposal was submitted in 2019 but was not funded.

Patient partners remained engaged in the development of a Research Centers in Minority Institutions (RCMI) program grant from the National Institute for Minority Health and Health Disparities. Patient partners and workgroup members were collaborators in the community engagement core of that grant proposal, which was awarded by RCMI in September 2020 (2 U54 MD00760527A1). An additional R15 grant proposal was submitted in February 2021.

\section{DISCUSSION}

This project demonstrates a successful patient-centered model to engage minority elderly populations with polypharmacy in identifying problems and making shared decisions on research strategies. Patient partners identified 7 potential ADE-related problems. They reported confusion about receiving prescriptions from different providers and worried about potential drug interactions. They also noted that most medical providers prescribe based on medication histories obtained verbally from patients without access to their official patient charts. A stunning $65 \%$ of town hall survey participants reported not maintaining a home medication list and would be unable to tell a provider what they are taking in an emergency.

The problems identified by this workgroup are similar to those developed by professional experts from the American College of Cardiology (ACC), the American Geriatrics Society (AGS), and the National Institute on Aging (NIA). ${ }^{14}$ According to the ACC/AGS/NIA guidelines, the most critical research problem among patients with polypharmacy is the coordination of care/ medications in patients with multiple comorbidities managed by multiple providers. ${ }^{14}$ Further intervention is needed to solve this critical problem to enhance medication safety in this community.

The complexity of the medication regimen has been associated with increased cost-related nonadherence in the elderly population. ${ }^{26}$ About $42 \%$ of the survey participants disagreed that their medications cost affected adherence negatively. Patient partners in the workgroup (with polypharmacy) also expressed a similar opinion when ranking the most critical research problem. Our 
study was limited in that the town hall survey did not capture the presence of drug insurance or the number of medications taken. Cost-related nonadherence will be higher if a patient is taking multiple medications without insurance or with limited insurance coverage. However, residents without insurance can apply for county discount cards or federally qualified health centers and receive medications with restricted formulary in minimal fees. In a workgroup meeting, a patient partner who had polypharmacy expressed that her medication cost was reduced by using discount plans by Harris County and promotions from retail pharmacies, which can cost as little as $\$ 4$ per month. A study by Watanabe et al reported that actual cost of medication use extended beyond just the cost of purchasing the medications. ${ }^{27}$ The estimated cost associated with nonoptimized medication therapy due to treatment failure was up to $\$ 528.4$ billion in 2016 .

Another limitation of our study was that it recruited seniors from a community exercise/health promotion program through the university-based geriatric resources network. Therefore, patients who were disabled, were bedridden, or lacked interest in exercise and health promotion activities were not included. Most workgroup and town hall participants were female, and this could limit the applicability of the result to male elderly patients. Patient partners and town hall participants varied in literacy level and knowledge in the use of electronic devices, and this could affect the result of the study.

Another observation was that close to half of the survey participants $(45 \%)$ reported they disagreed that they forgot to take their medications. The lack of perceived forgetfulness in taking medications has been reported and potentially due to social desirability bias, in which patients tell the provider what they want to hear to avoid embarrassment. $^{28}$

Patient partners were fully engaged in shared decisionmaking during each meeting, and the attendance to workgroup meetings was optimal $(100 \%$ for 2 patients and 1 caregiver, and $60 \%$ for 1 patient). This success can be explained by clear communication in each workgroup meeting. Health educators who were responsible for senior activities assisted tremendously in reminding patient partners about meetings. Each meeting date was discussed and agreed to through face-to-face interaction at the previous meeting. Additionally, patient partners communicated with investigators between meetings about ideas, articles, and questions about the upcoming meeting.

The success in having a high attendance for the community town hall meeting was assisted by health educators calling each senior in the network about the event and peer advertisements by the patient partners in the workgroup. Patient partners were allowed to volunteer as speakers on the panel. Some were hesitant to join at first, but eventually, all 3 patient partners and the caregiver partner stepped up to share their experiences in the town hall meeting.

\section{CONCLUSIONS}

This narrative provides a roadmap for conducting multidisciplinary, patient-centered participatory research to answer complex clinical questions. The next step includes refining the procedures described herein to continuously improve community-engagement strategies and promote shared decision-making in the development of interventions aimed at minimizing the adverse drug events that occur due to multiple drug therapies among elderly patients with multiple comorbidities.

\section{Patient-Friendly Recap}

- Improper taking of medications by elderly patients prescribed multiple drugs for multiple conditions can lead to serious adverse events.

-With the goal of informing a research proposal aimed at improving medication management, authors engaged seniors from a historically African American community to participate in workgroup and town hall meetings.

- Common problems reported by patient partners were doubts about drug advertisements and interactions between drugs.

- Most seniors were more comfortable receiving faceto-face medication counseling vs app/virtual visits.

\section{Author Contributions}

Study design: Poon, Skelton, Bean, Guinn, Jemerson. Data acquisition or analysis: all authors. Manuscript drafting: all authors. Critical revision: Poon, Skelton, Mbue, Charles, Ndefo.

\section{Conflicts of Interest}

None.

\section{Funding Sources}

This project was funded by the Patient-Centered Outcomes Research Institute Pipeline to Proposal Award (PA133-7709677). Additional funding disclosure for Dr. Poon: Research reported in this publication was supported in part by the National Institute on Minority Health and Health Disparities of the National Institutes of Health under award no. U54MD007605. The content is solely the responsibility of the authors and does not necessarily represent the official views of the National Institutes of Health. Additional funding disclosures for Dr. Skelton: This material is based on work supported (or supported in part) by the U.S. Department of Veterans 
Affairs, Veterans Health Administration, Office of Research and Development, and the Center for Innovations in Quality, Effectiveness and Safety (CIN 13-413), Health Services Research \& Development Career Development Award (1 IK2 HX00248403), and the Health Resources \& Services Administration for the project titled "Baylor College of Medicine Center of Excellence in Health Equity, Training \& Research" (1 D34 HP31024-01-00).

\section{References}

1. Kohn LT, Corrigan JM, Donaldson MS; Institute of Medicine (US) Committee on Quality of Health Care in America (eds). To Err is Human: Building a Safer Health System. National Academy Press; 2000.

2. Bourgeois FT, Shannon MW, Valim C, Mandl KD. Adverse drug events in the outpatient setting: an 11-year national analysis. Pharmacoepidemiol Drug Saf. 2010;19:901-10. CrossRef

3. Budnitz DS, Pollock DA, Weidenbach KN, Mendelsohn AB, Schroeder TJ, Annest JL. National surveillance of emergency department visits for outpatient adverse drug events. JAMA. 2006;296:1858-66. CrossRef

4. U.S. Department of Health and Human Services, Administration for Community Living. Profile of older Americans [2018]. Page last modified July 21, 2020; accessed August 17, 2020. https://acl.gov/aging-and-disability-in-america/data-andresearch/profile-older-americans

5. Shepherd G, Mohorn P, Yacoub K, May DW. Adverse drug reaction deaths reported in the United States vital statistics, 1999-2006. Ann Pharmacother. 2012;46:169-75. CrossRef

6. Shehab N, Lovegrove MC, Geller AI, et al. US emergency department visits for outpatient adverse drug events, 20132014. JAMA. 2016;316:2115-25. CrossRef

7. Gerteis J, Izrael D, Deitz D, et al. Multiple Chronic Conditions Chartbook. AHRQ Pub. No. Q14-0038. Agency for Healthcare Research and Quality; April 2014.

8. Qato DM, Alexander GC, Conti RM, Johnson M, Schumm $\mathrm{P}$, Lindau ST. Use of prescription and over-the-counter medications and dietary supplements among older adults in the United States. JAMA. 2008;300:2867-78. CrossRef

9. Schatz SN, Weber RJ. Adverse drug reactions. In: Murphy JE, Lee MW (eds). PSAP 2015 Book 2 CNS/Pharmacy Practice: Pharmacotherapy Self-Assessment Program. American College of Clinical Pharmacy; 2015.

10. Centers for Medicare \& Medicaid Services. Partnership for patients. Page last updated July 24, 2020; accessed April 22, 2020. https://partnershipforpatients.cms.gov/p4p resources/ tsp-adversedrugevents/tooladversedrugeventsade.html

11. Anderson LJ, Schnipper JL, Nuckols TK, et al. Effect of medication reconciliation interventions on outcomes: a systematic overview of systematic reviews. Am J Health Syst Pharm. 2019;76:2028-40. CrossRef

12. Ross SB, Wu PE, Atique A, et al. Adverse drug events in older adults: review of adjudication methods in deprescribing studies. J Am Geriatr Soc. 2020;68:1594-602. CrossRef

13. Kim JM, Suarez-Cuervo C, Berger Z, et al. Evaluation of patient and family engagement strategies to improve medication safety. Patient. 2018;11:193-206. CrossRef

14. Schwartz JB, Schmader KE, Hanlon JT, et al. Pharmacotherapy in older adults with cardiovascular disease: report from an American College of Cardiology, American Geriatrics Society, and National Institute on Aging Workshop. J Am Geriatr Soc. 2019;67:371-80. CrossRef
15. City of Houston Planning and Development Department. Super neighborhood resource assessment, [No. 67 Greater Third Ward]. Published November 2017; accessed April 23, 2020. https://www.houstontx.gov/planning/Demographics/ docs pdfs/SN/67 Greater ThirdWard.pdf

16. Stanton R. Two Houston neighborhoods called most dangerous in the U.S. Houston Chronicle. Published May 1, 2013; accessed April 23, 2020. https://www.chron.com/business/ real-estate/article/Two-Houston-neighborhoods-called-mostdangerous-4476367.php

17. White CL, Overbaugh KJ, Pickering CE, et al. Advancing care for family caregivers of persons with dementia through caregiver and community partnerships. Res Involv Engagem. 2018;4:1. CrossRef

18. Sheridan S, Schrandt S, Forsythe L, Hilliard TS, Paez KA; Advisory Panel on Patient Engagement (2013 inaugural panel). The PCORI Engagement Rubric: promising practices for partnering in research. Ann Fam Med. 2017;15:165-70. CrossRef

19. Stingl JC, Kaumanns KL, Claus K, et al. Individualized versus standardized risk assessment in patients at high risk for adverse drug reactions (IDrug) - study protocol for a pragmatic randomized controlled trial. BMC Fam Pract. 2016;17:49. CrossRef

20. Chau SH, Jansen AP, van de Ven PM, Hoogland P, Elders PJ, Hugtenburg JG. Clinical medication reviews in elderly patients with polypharmacy: a cross-sectional study on drug-related problems in the Netherlands. Int J Clin Pharm. 2016;38:46-53. CrossRef

21. Mangin D, Bahat G, Golomb BA, et al. International Group for Reducing Inappropriate Medication Use \& Polypharmacy (IGRIMUP): position statement and 10 recommendations for action. Drugs Aging. 2018;35:575-87. CrossRef

22. Kovačević SV, Miljković B, Ćulafić M, et al. Evaluation of drug-related problems in older polypharmacy primary care patients. J Eval Clin Pract. 2017;23:860-5. CrossRef

23. Lampela P, Hartikainen S, Lavikainen P, Sulkava R, Huupponen R. Effects of medication assessment as part of a comprehensive geriatric assessment on drug use over a 1-year period: a population-based intervention study. Drugs Aging. 2010;27:507-21. CrossRef

24. Campins L, Serra-Prat M, Gózalo I, et al. Randomized controlled trial of an intervention to improve drug appropriateness in community-dwelling polymedicated elderly people. Fam Pract. 2017;34:36-42. CrossRef

25. Almalki M, Gray K, Sanchez FM. The use of self-quantification systems for personal health information: big data management activities and prospects. Health Inf Sci Syst. 2015;3(Suppl 1):S1. CrossRef

26. Gu D, Shen C. Assessing the importance of factors associated with cost-related nonadherence to medication for older US Medicare beneficiaries. Drugs Aging. 2019;36:1111-21. CrossRef

27. Watanabe JH, McInnis T, Hirsch JD. Cost of prescription drug-related morbidity and mortality. Ann Pharmacother. 2018;52:829-37. CrossRef

28. Brown MT, Bussell J, Dutta S, David K, Strong S, Mathew S. Medication adherence: truth and consequences. Am J Med Sci. 2016;351:387-99. CrossRef

(C) 2021 Advocate Aurora Health, Inc. 